\title{
STUDY ON LEVEL OF VEGETATION LAND FRAGMENTATION IN WESTERN PROVINCE, SRI LANKA
}

\author{
RANAWEERA. M.N.N. ${ }^{1 *}$, JAYASINGHE. A.B. ${ }^{2}$ \& ABENAYAKE C. ${ }^{3}$ \\ 1,2Urban Simulation Lab, Department of Town and Country Planning, University of Moratuwa, Moratuwa, Sri Lanka \\ ${ }^{3}$ Department of Town and Country Planning, University of Moratuwa, Moratuwa, Sri Lanka \\ ${ }^{1}$ nesharanaweera29@gmail.com, ${ }^{2}$ amilabj@uom.lk, ${ }^{3}$ chethika@uom.lk
}

\begin{abstract}
Muthurajawela Marsh and Negombo Lagoon have lost their marshland and mangroves from $41 \%$ and $21 \%$ accordingly from 1997 to 2017. Vegetation land fragmentation (VLF) is the foremost reason that accelerates the vegetation cover change. However, Sri Lanka has not been given sufficient attention to investigate VLF with case studies. Further, fragmentation patterns like dissecting, shrinking, and disappearing are still essential to investigate with empirical studies to comprehend the phases of VLF. Therefore, this study attempts to quantify the level of vegetation land fragmentation (LVLF) in the Western Province's Grama Niladhari Divisions (GNDs) from 2000 to 2020 by applying the Landscape Division Index (FRAGSTATS). It further analyses the patterns of VLF by using 200 fragmented locations. The key findings demonstrate that $54 \%$ of GNDs have more than $60 \%$ of the LVLF in the Gampaha District from 2000 to 2010. Although it has reduced up to 49\% from 2010-2020, the Gampaha District remains in the highest position. It additionally discloses the significant increment in LVLF along the expressways from 2010 to 2020. $46 \%$ of fragmented patches indicate the mixed of dissecting, shrinking, and disappearing patterns. Therefore, the study provides methodological application and quantitative insights for planners to investigate VLF and its patterns.
\end{abstract}

Keywords: Vegetation Land Fragmentation, Fragmentation Patterns, Spatial Planning, Landscape Ecology, Western Province of Sri Lanka

\section{Introduction}

Vegetation land fragmentation refers to the dispersion or division of land parcels or patches into smaller ones (Kili'c, et al., 2019; Forman, 2014; Wei \& Zhang, 2011). It further creates a barrier to the optimal function of the lands (Wei \& Zhang, 2011). Vegetation land fragmentation denotes the Landscape Ecological theory (Forman, 2014; Wu, 2013). It is further explained under the Patch-Corridor-Matrix model (Hedblom, 2008; Thiele, et al., 2008). Further, it leads to the irregularity and complexity in the urban morphology and its effect on sustainable development (Saganeiti, et al., 2018; Irwin* $¥ ¥ \&$ Bockstael§, 2007; Verburg, et al., 2004). Vegetation land fragmentation creates an impact on biodiversity and habitat isolation (Hudecova, et al., 2018; Un, et al., 2008). Further, it leads to attract Greenfield development that can destroy entire ecosystems (Barau \& Qureshi, 2015; York, et al., 2011). It is evident from the empirical studies that vegetation land cover in Sri Lanka is significantly diminishing specifically within the urbanized areas (Athukorala, et al., 2021). Urban Wetland Ecosystems in the Western Province are major examples of their vegetation loss (Athukorala, et al., 2021). Muthurajawela Marsh and Negombo Lagoon have lost their marshland and mangroves from 41\% and 21\% accordingly from 1997 to 2017 (Athukorala, et al., 2021). Therefore, this vegetation cover changes, and their fragmentation into smaller parcels causes habitat isolation (Athukorala, et al., 2021; Forman, 2014). Vegetation land fragmentation is the main reason that accelerates the vegetation cover change in ecosystems (Forman, 2014; Huang, 2014). It directly influences on sustainable development (You, 2016). Further, vegetation land fragmentation leads to social segregation (Altinok \& Cengiz, 2016). Expressway developments, road developments, and infrastructure developments segregate the existing community from their social interactions and livelihood (Altinok \& Cengiz, 2016; You, 2016; Skog, 2016; Li, et al., 2010). At the same time, vegetation land fragmentation generates economic impacts on the lands as well as on the peoples' income sources (Liu, et al., 2017; You, 2016). Paddy land 
fragmentation is a major example of the economic impacts of land fragmentation (Wickramaarachchi \& Weerahewa, 2016). Therefore, it is important to study the level of vegetation land fragmentation in the Sri Lankan context.

Landscape metrics have been used to quantify vegetation land fragmentation in many studies (Barau \& Qureshi, 2015; Bereitschaft \& Debbage, 2013). Such as the number of patches, patch density, edge density, area-weighted fractal dimension, division index, and so on (Saganeiti, et al., 2018; Hudecova, et al., 2018; Huang, 2014). FRAGSTATS is the major software that uses to quantify the landscape metrics (Forman, 2014; Bereitschaft \& Debbage, 2013). Classified satellite images use as the input file of metrics calculations (Balcik, 2016). Several studies have been proved the relationships between economic, social, and environmental factors with vegetation land fragmentation (You, 2016). For example, population density has a positive relationship with vegetation land fragmentation (Skog, 2016; Barau \& Qureshi, 2015). Roads or corridor development leads the vegetation land fragmentation and its dispersion of land parcels (Schumacher \& Deilmann, 2019; Li, et al., 2019; Li, et al., 2010). Between decentralized economic policies and land fragmentation, has a positive relationship (You, 2016). The Patch-Corridor-Matrix model explains how the intensity of vegetation land fragmentation differs with the vegetation land size, shape, and association (Forman, 2014; Thiele, et al., 2008). The size of the ecological land and the smoothness of the edges have significant relationships with land fragmentation (Liang, et al., 2020; Wu, 2013; Hedblom, 2008).

There are very limited but successful researches have been conducted regarding vegetation land fragmentation. However, it is significant from literature; land fragmentation is significantly investigated in the Western and Eastern parts of the world (Schumacher \& Deilmann, 2019; Bereitschaft \& Debbage, 2013; Marinescu \& Avram, 2012). Unfortunately, Sri Lanka like a South Asian country has not been given sufficient attention to investigate land fragmentation and its impacts (Athukorala, et al., 2021; Wickramaarachchi \& Weerahewa, 2016). Therefore, it is necessary to study the pattern of land fragmentation in the Sri Lankan context. Although there are quantification methods to quantify the vegetation land fragmentation, those methods have not been applied in the Sri Lankan Context (Athukorala, et al., 2021). More importantly, enough attention has not been given to synthesize the pattern of vegetation land fragmentation (Liang, et al., 2020). Few studies explain numerous types of vegetation land fragmentation. They are perforating, incising, dissecting, shrinking, attrition, and disappearing (Forman, 2014; $\mathrm{Wu}, 2013$; Jaeger, 2000). However, it is essential to study the pattern of vegetation land fragmentation with several empirical studies to comprehend the phases of vegetation land fragmentation.

Considering the specified research gaps, the research objective is to quantify the level of vegetation land fragmentation in Western Province, Sri Lanka. Further, the study analyzes the level of vegetation land fragmentation by the district level. Another objective of this study is to analyze the pattern of vegetation land fragmentation in Western Province, Sri Lanka. Therefore, the research addresses the following research questions.

1. What is the spatial distribution of the level of vegetation land fragmentation in WesternProvince?

2. What is the level of vegetation land fragmentation by the district level?

3. What are the patterns of vegetation land fragmentation in Western Province?

The study scope is limited to the vegetation land use category in Western Province, Sri Lanka. The analysis is limited to 2000,2010 to 2020 periods. The applied quantification method is only the Landscape Division index since the study focus is to quantify the division or fragmented level. However, the study contains the comprehensive quantification process of vegetation land fragmentation.

\section{Material and Method}

The study followed an all-inclusive methodology to achieve the research objectives. The selected case study for research is the Western Province, Sri Lanka. The Western Province was selected considering its rapid urbanization level. The further entire province was selected to compare Colombo, Gampaha, and Kaluthara Districts. Vegetation land fragmentation was calculated for each GND in Western Province. Since GNDs can show the spatial variations at the local level within the province. The other reason for choosing GND boundaries instead of patches is, this study has the intention of analyzing factors of LVLF and developing a modeling framework in future studies. Therefore, considering data availability like population, the study chooses to quantify the LVLF at the GND level to use the results of this study for model development. 
The study contains three main methodological stages to fulfill the research objectives. The following are the key stages.

1. Quantify the overall level of vegetation land fragmentation by GND

2. Analyze the spatial distribution of level of vegetation land fragmentation

3. Analyze the patterns of vegetation land fragmentation

\subsection{QUANTIFY OVERALL LEVEL OF VEGETATION LAND FRAGMENTATION BY GND}

The level of vegetation land fragmentation (LVLF) refers to the change or growth of the vegetation land fragmentation (VLF) comparing to the initial year in percentage (Figure 1). Therefore, the level of vegetation land fragmentation can be specified as follows.

$$
\text { Level of vegetation land fragmentation }(L V L F)=\frac{V L F \text { of year } 2-V L F \text { of year } 1}{V L F \text { of year } 1}
$$

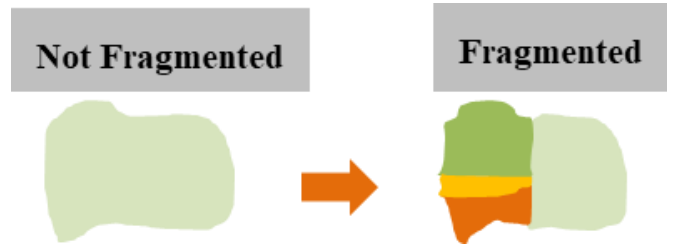

Figure 1, Level of vegetation land fragmentation (Source: Compiled by Author)

The study computed vegetation land fragmentation (VLF) to compute the level of land fragmentation (LVLF) at the initial level. The applied method to quantify the vegetation land fragmentation is landscape metrics. The use landscape metric is the Landscape Division Index at the class level. It is a landscape metric that is available in FRAGSTATS software. The Landscape Division Index measures the division of the same land use category by identifying random pixels in the given area. It calculates the probability of two random pixels are not in the same patch (Jaeger, 2000).

$$
\text { Landscape Division Index }=\left[1-\sum_{i=1}^{n} * \sum_{j=1}^{n}\left(\frac{a_{i j}{ }^{2}}{A}\right)\right]
$$

' $\mathrm{A}$ ' denotes the total landscape area. 'aij' is the area of patch ij. The value of the Landscape Division Index lies between 0 to 1 . If the value is 0 , that area is not fragmented. When the value is closer to 1 , the land has been extremely fragmented. If $j$ and i pixels are within the same patch, the value will be zero (Figure 2). If $j$ and i pixels are in separate patches, the value lies between 0 to 1(Figure 2). However, if $i$ and j pixels situate within smaller patches, the division value will be closer to the one (Figure 2).

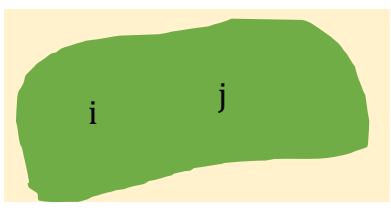

0

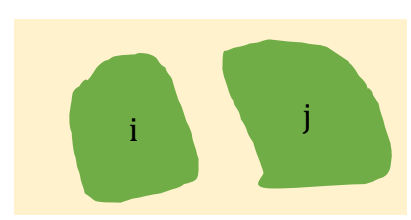

$0-0.5$

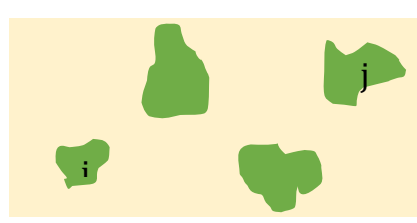

$0.5-1$

Figure 2, Landscape division index's value explanation (Source: Compiled by Author)

\subsubsection{Computation process of level of vegetation land fragmentation}

The study used 2505 GND shape files of the Survey Department in Sri Lanka. For the supervised classification, the USGS platform was used to get the satellite images for 2000, 2010, and 2020(Landsat 7 and 8 satellite images). The study used GIS applications to generate the raster outputs (TIFF) to create the input file of FRAGSTATS. FRAGSTATS is the most famous and reliable software that can use to analyze landscape metrics (Bereitschaft \& Debbage, 2013). Since there are 2505 raster inputs. The study created a 
batch file (.fbt) to run the Landscape Division Index. Then the exported output of the FRAGSTATS joined with the GNDs to calculate the level of vegetation land fragmentation. Then, Maps were created by using QGIS to display the results and their spatial distribution. At last, the study analyzed the level of vegetation land fragmentation by districts.

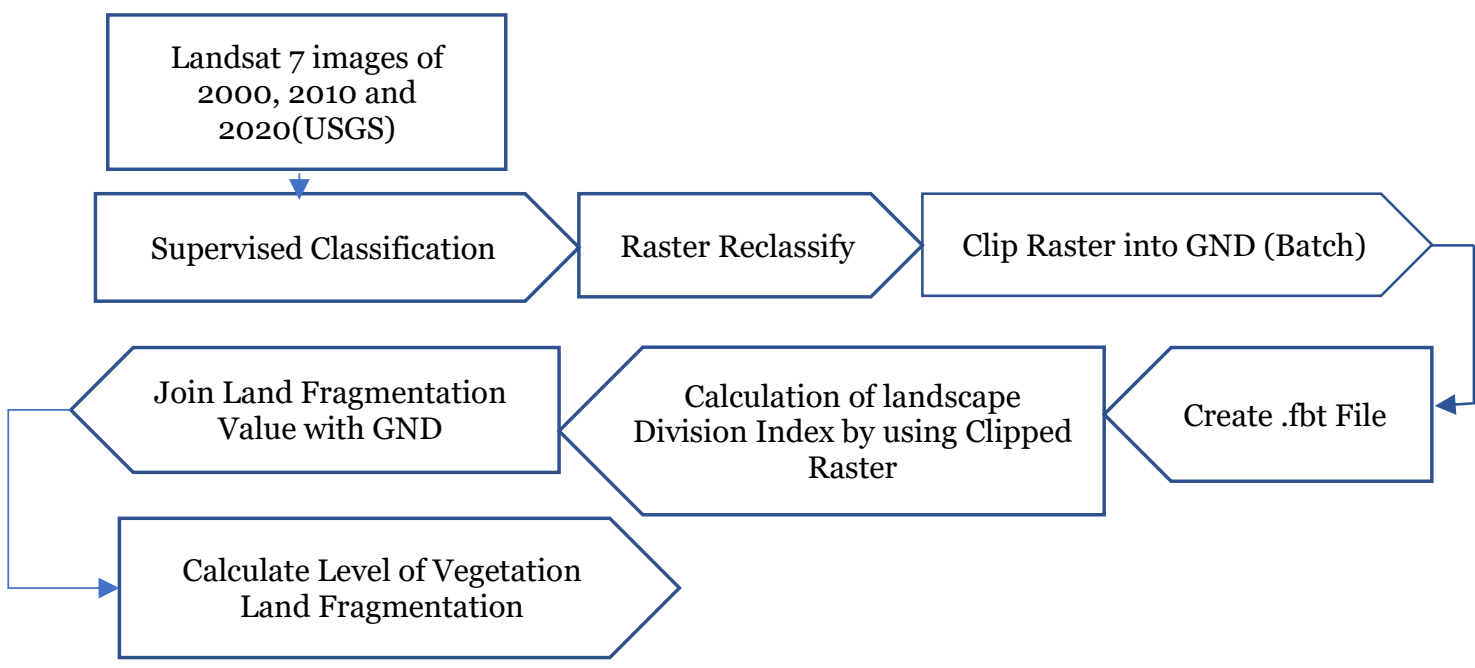

Figure 3, Computation process of vegetation land fragmentation (Source: Compiled by Author)

\subsection{ANALYZE THE SPATIAL DISTRIBUTION OF LEVEL OF VEGETATION LAND FRAGMENTATION}

The calculated level of vegetation land fragmentation was analyzed by district level to explore the character of the vegetation land fragmentation. Here, Microsoft Excel was used to analyze the statistical results. The level of vegetation land fragmentation was classified into five levels. They are less than $20 \%, 20 \%-40 \%$, $40 \%-60 \%, 60 \%-80 \%$ and more than $80 \%$. Then classified data are analyzed by district level. The percentage of the level of vegetation land fragmentation for each class for each district was analyzed comparing to the total classification.

\subsection{ANALYZE THE PATTERNS OF VEGETATION LAND FRAGMENTATION}

The pattern of the vegetation land fragmentation was identified based on the 200 identified fragmented locations within the Western Province. The identified locations were limited to 200 because of the availability of clear images during the different periods and available time concern. However, 200 locations reflect the $20-30 \%$ GND with more than $60 \%$ of the level of vegetation land fragmentation. Because 955 GNDs from 2505 belong to more than $60 \%$ of vegetation land fragmentation. Therefore, 200 locations represent 20. $94 \%$ of the sample size out of the total. Google Earth's satellite images and its time comparison tool were used to identify the vegetation fragmented locations. Locations were identified from 2000 to 2020 . However, the same year comparison cannot show in every location because of the availability and visual quality of the satellite images. The identified locations are classified into the patterns of Dissecting+Shrinking+Disapering, Shrinking+Disapering, and Dissecting+Shrinking by considering the majority of phases. At last, statistical analysis was conducted to show the percentage of each pattern of vegetation land fragmentation.

\section{Results and Discussion}

As discussed in the methodological section, the results explain under three main stages. They are the overall level of vegetation land fragmentation, the level of vegetation land fragmentation by the district level, and the pattern of the vegetation land fragmentation.

\subsection{OVERALL LEVEL OF VEGETATION LAND FRAGMENTATION IN WESTERN PROVINCE}

The level of vegetation land fragmentation (Figure 4) from 2000-2010 and 2010-2020 will explain in this section. It explains the spatial distribution of the level of vegetation land fragmentation.

The results of 2000 to 2010 indicate a higher level of vegetation land fragmentation in most of the 
GNDs in the Gampaha District. It is more significant in the inner areas and along the main roads. Gampaha, Nittabuwa, Mirigama areas show significant increment in vegetation land fragmentation in the Gampaha District from 2000 to 2010. Colombo's core area displays a lower level of vegetation land fragmentation. Homagama, Padukka, Hanwella, and Kosgama suburban areas show a moderate and higher level of vegetation land fragmentation. The Kaluthara District expresses a significantly lower level of vegetation land fragmentation. However, the Mathugama area indicates a higher level of vegetation land fragmentation from 2000 to 2010.

The 2010 to 2020 level of vegetation land fragmentation illustrates a higher intensity along the expressways' interchanges and their adjacent areas. Significantly, Colombo's core area shows a lower level of vegetation land fragmentation by continuing the same pattern of 2000 to 2010. However, Inner areas and the eastern part of the Western Province exhibit an ominously higher level of vegetation land fragmentation. Areas like Padukka, Kottawa, Homagama, Dodangoda, Bulathsinhala, Mathugama, Veyangoda, Kadawatha, Nittabuwa, Gampaha, Divlapitiya, Ja-Ela areas indicate a significant level of vegetation land fragmentation. However, 2010-2020 also shows a higher level of vegetation land fragmentation in most of the areas in the Gampaha District than the other two districts. The Kaluthara District indicates a significant improvement in the level of vegetation land fragmentation compared to 2000 to 2010 .

\subsection{LEVEL OF VEGETATION LAND FRAGMENTATION BY DISTRICT LEVEL}

The level of vegetation land fragmentation of each GND by the district level from 2000-2010 (Figure 5) shows $54 \%$ of GNDs with more than $60 \%$ level of vegetation land fragmentation in the Gampaha District. Further, the more than $80 \%$ level of vegetation land fragmentation in the Gampaha District is $84 \%$ compared to the total number of GNDs with more than $80 \%$ level of vegetation land fragmentation(Figure 6). However, the Colombo District indicates a low and moderate level of vegetation land fragmentation. Because $36 \%$ of GNDs have $20 \%-40 \%$ of the level of vegetation land fragmentation and $18 \%$ of GNDs have a moderate level of vegetation land fragmentation(Figure 5). The Kaluthara District indicates that $23 \%$ of GNDs have less than $20 \%$ of the level of vegetation land fragmentation (Figure 5). It is $42 \%$ compared to the total number of GNDs that are less than $20 \%$ class(Figure 6).

2010-2020 statistical comparison also indicates that the Gampaha District contains 49\% of GND with more than $60 \%$ of the level of vegetation land fragmentation (Figure 7). Although it has reduced up to 49\% from 54\%, the Gampaha District remains in the highest position. The total number of GNDs of the Gampaha District with more than $80 \%$ level of vegetation land fragmentation is $53 \%$ (Figure 8). The Kaluthara District expresses a moderate level of vegetation land fragmentation. $25 \%$ of GND in the Kaluthara District shows the $40 \%-60 \%$ level of vegetation land fragmentation (Figure 7 ). It is $36 \%$ of the total (Figure 8). However, the Kaluthara District specifies 10\% of GND with a lower than $20 \%$ level of vegetation land fragmentation (Figure 7). It is $46 \%$ of the total (Figure 8). The Colombo District displays a minor level of vegetation land fragmentation. Because the number of GND with $20 \%-40 \%$ is $53 \%$ (Figure 7) and it is $49 \%$ (Figure 8 ) of the total. Therefore, statistical districts' comparison analysis reveals the same pattern from 2000-2010 and 2010-2020 with slight differences.

\begin{tabular}{|c|c|c|c|c|c|c|c|c|c|c|}
\hline \multirow{2}{*}{ Districts } & \multicolumn{5}{|c|}{$\%(2000-2010)$} & \multicolumn{5}{|c|}{$\%$ Out of Total (2000-2010) } \\
\hline & $<20 \%$ & $\begin{array}{l}20 \%- \\
40 \%\end{array}$ & $\begin{array}{l}40 \%- \\
60 \%\end{array}$ & $\begin{array}{l}60 \%- \\
80 \%\end{array}$ & $>80 \%$ & $<20 \%$ & $\begin{array}{l}20 \%- \\
40 \%\end{array}$ & $\begin{array}{l}40 \%- \\
60 \%\end{array}$ & $\begin{array}{l}60 \%- \\
80 \%\end{array}$ & $>80 \%$ \\
\hline Gampaha & 4.9 & 18.8 & 21.7 & 45.5 & 9.2 & 8.9 & 19.9 & 35.1 & 58.5 & 84.5 \\
\hline Kaluthara & 23.4 & 39.5 & 21.9 & 14.4 & 0.8 & 42.2 & 41.9 & 35.5 & 18.6 & 7.2 \\
\hline Colombo & 27.1 & 36.1 & 18.1 & 17.8 & 0.9 & 48.9 & 38.2 & 29.4 & 22.9 & 8.3 \\
\hline Districts & \multicolumn{5}{|c|}{$\%(2010-2020)$} & \multicolumn{5}{|c|}{$\%$ Out of Total (2010-2020) } \\
\hline Gampaha & 3.5 & 22.4 & 25.3 & 36.1 & 12.7 & 15.7 & 20.7 & 36.7 & 47.3 & 53.0 \\
\hline Kaluthara & 10.2 & 33.3 & 25.1 & 22.3 & 9.1 & 46.2 & 30.7 & 36.3 & 29.2 & 37.9 \\
\hline Colombo & 8.4 & 52.8 & 18.7 & 18.0 & 2.2 & 38.1 & 48.6 & 27.0 & 23.5 & 9.0 \\
\hline
\end{tabular}

Table 1, Level of vegetation land fragmentation by districts 

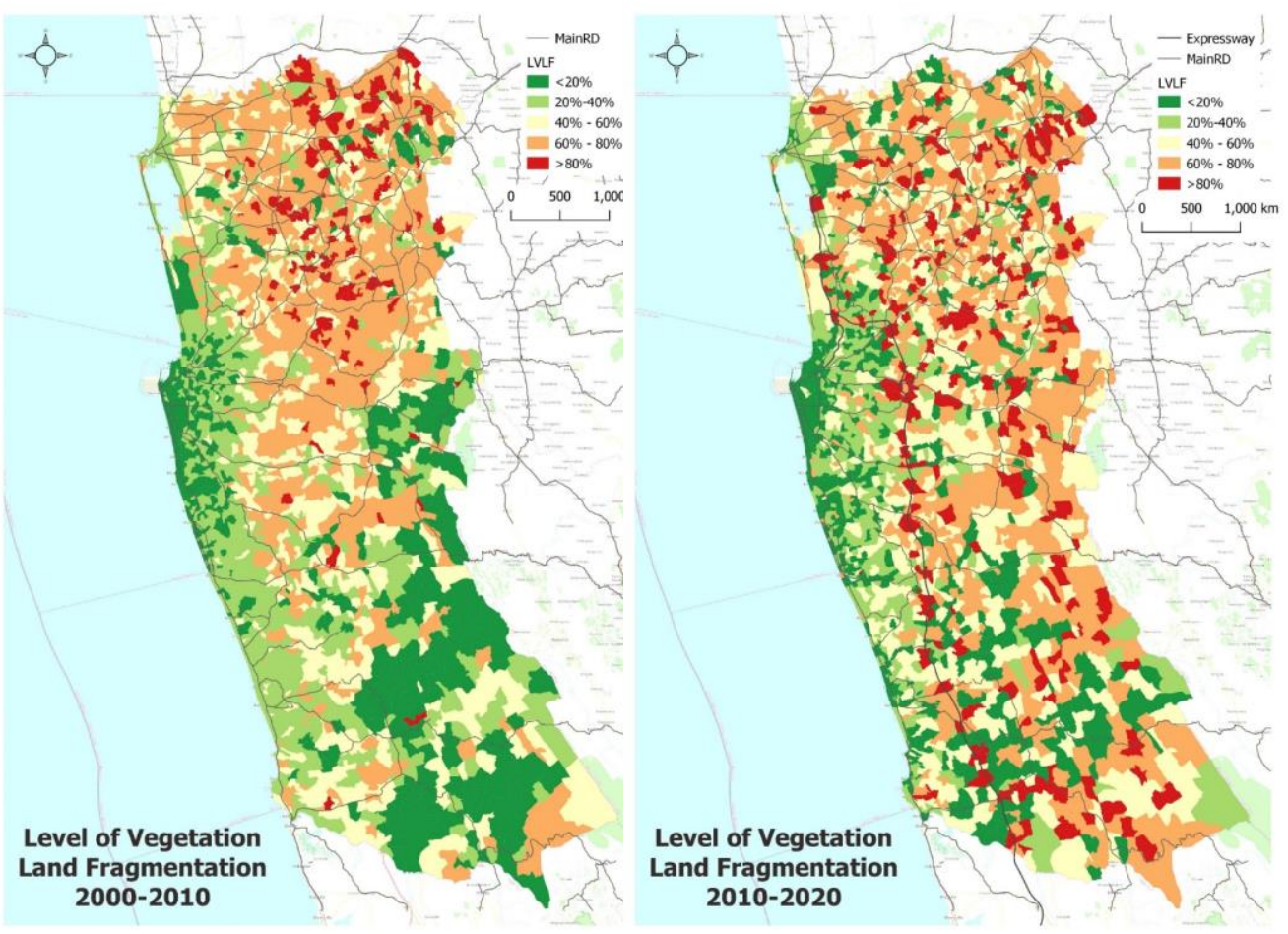

Figure 4, Level of vegetation land fragmentation 2000-2010(Source: Compiled by Author)

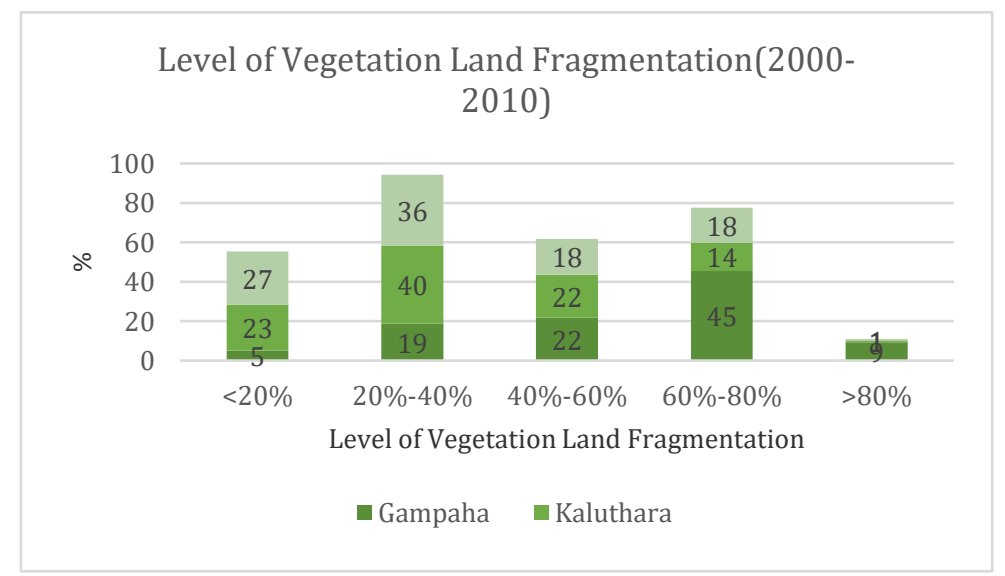

Figure 5, District comparison of LVLF 2000-2010(Source: Compiled by Author)

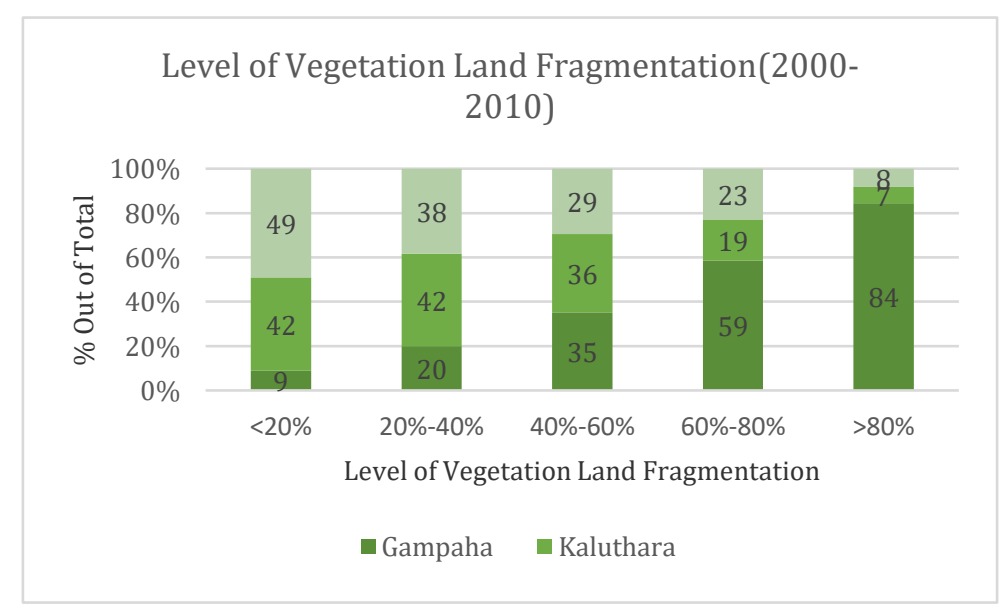

Figure 6, Total distribution of the LVLF 2000-2010 (Source: Compiled by Author) 


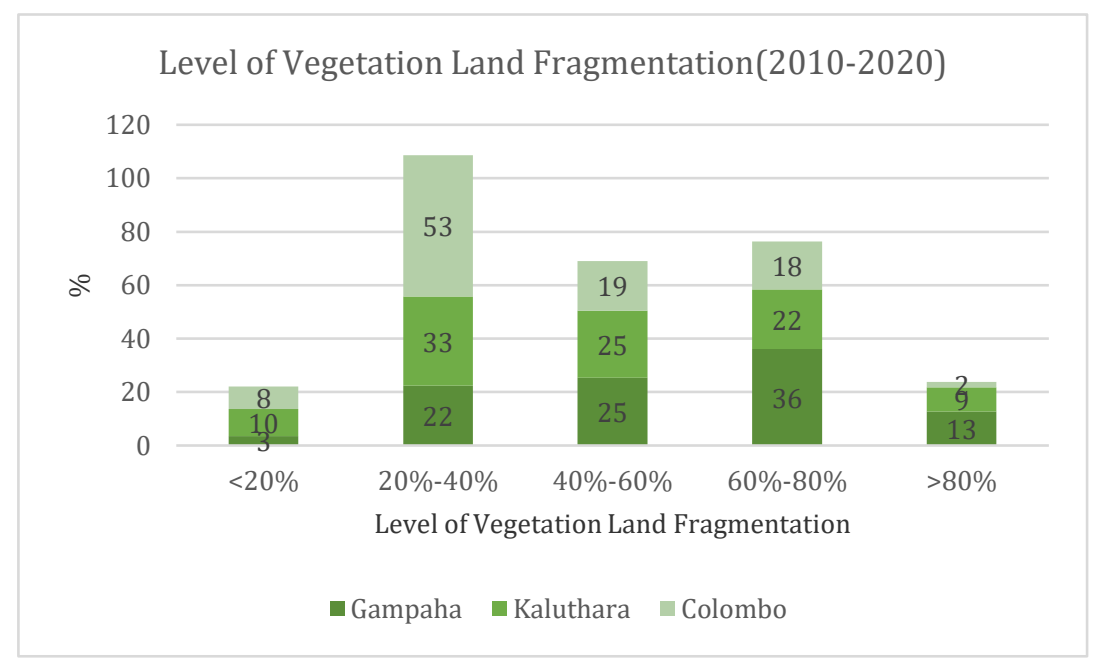

Figure 7, District comparison of LVLF 2010-2020 (Source: Compiled by Author)

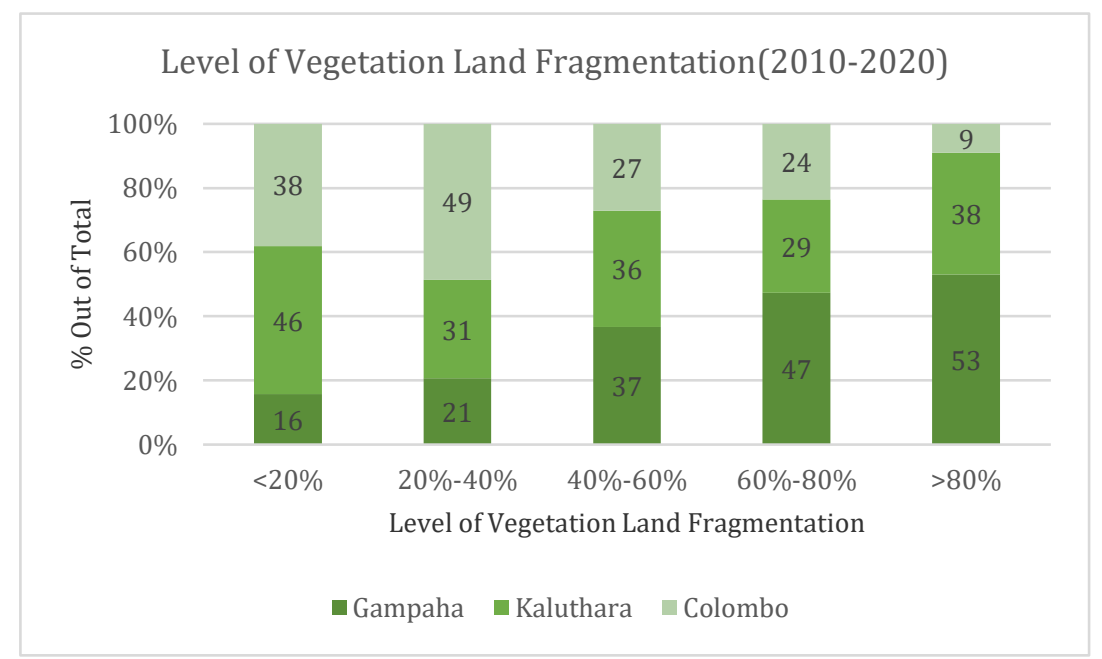

Figure 8, Total distribution of the LVLF 2010-2020 (Source: Compiled by Author)

\subsection{PATTERNS OF VEGETATION LAND FRAGMENTATION}

The identified 200 locations indicate mainly three types of patterns of vegetation land fragmentation (three types of scenarios). They are,

1. Scenario 1- Dissecting + Shrinking + Disappearing

2. Scenario 2- Shrinking + Disappearing

3. Scenario 3- Dissecting + Shrinking

Three examples are presented in Figure 9 representing the three main types of vegetation land fragmentation. Makubura's case shows that the vegetation patch has already been dissected when it was 2004, then the vegetation patch was shrinking until 2016. Now, the total vegetation patch has been disappeared. Adikarigoda's case specifies the second scenario. When it was 2019, the vegetation patch was shrinking, when it came to 2020 , half of the vegetation patch has been disappeared. Weediyawatta's case indicates the third scenario. The vegetation patch has been dissected by 2018. Now, the vegetation patch is shrinking. If this shrinking process continues, the entire vegetation patch can disappear like Makubura's case.

The statistical analysis of the patterns of the vegetation land fragmentation also indicates the intensity of each scenario compared to the total 200 locations. $46 \%$ of locations specify scenario 1 that is the combination of Dissecting + Shrinking + Disappearing (Figure 10). Within that, the Gampaha District has $51 \%$ of locations (Figure 11). $34 \%$ of locations show the pattern of Shrinking + Disappearing (Figure 10). 63\% of locations are situated in the Gampaha Districts from this pattern (Figure 11). The rest of the 
$20 \%$ appears Dissecting + Shrinking pattern. $50 \%$ of locations are situated in the Kaluthara District in the same pattern (Figure 11). Likewise, the study identifies mainly three patterns of vegetation land fragmentation.

\begin{tabular}{|l|r|r|r|r|r|r|}
\hline & \multicolumn{3}{|c|}{$\%$} & \multicolumn{3}{c|}{ \% Out of Total } \\
\cline { 2 - 7 } Districts & Scenario 1 & Scenario 2 & Scenario 3 & Scenario 1 & Scenario 2 & Scenario 3 \\
\hline Gampaha & 45.2 & 95.1 & 14.7 & 51.1 & 63.2 & 35.0 \\
\hline Kaluthara & 35.9 & 12.8 & 51.3 & 15.2 & 7.4 & 50.0 \\
\hline Colombo & 54.4 & 35.1 & 10.5 & 33.7 & 29.4 & 15.0 \\
\hline
\end{tabular}

Table 2, Patterns of vegetation land fragmentation by districts
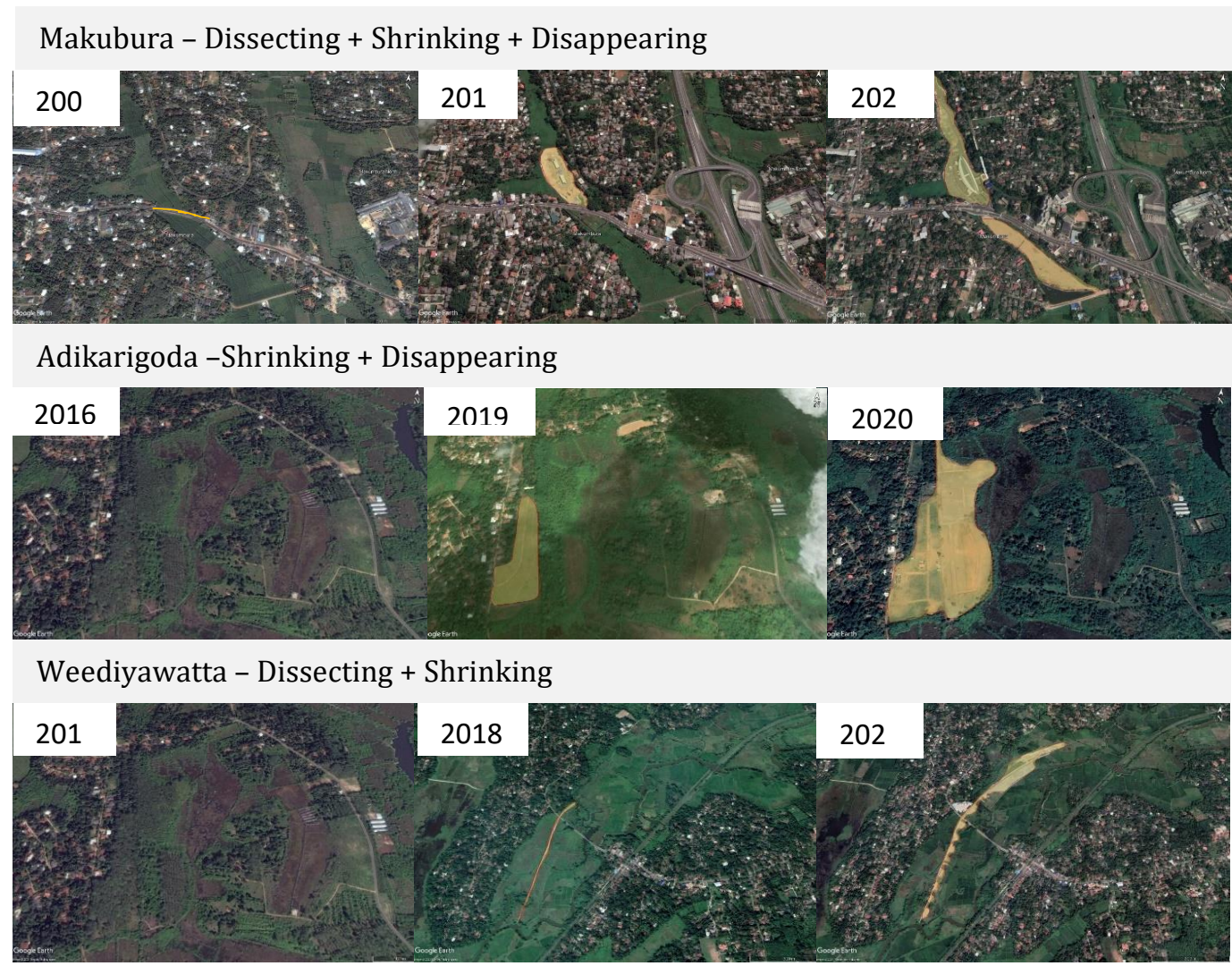

Figure 9, Patterns of vegetation land fragmentation (Source: Compiled by Author)

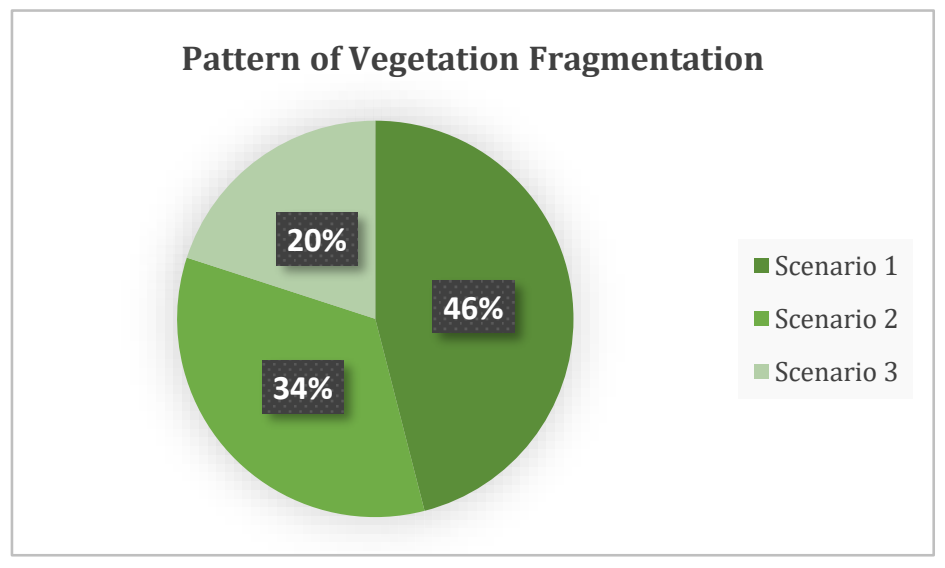

Figure 10, Distribution of patterns of vegetation fragmentation (Source: Compiled by Author) 


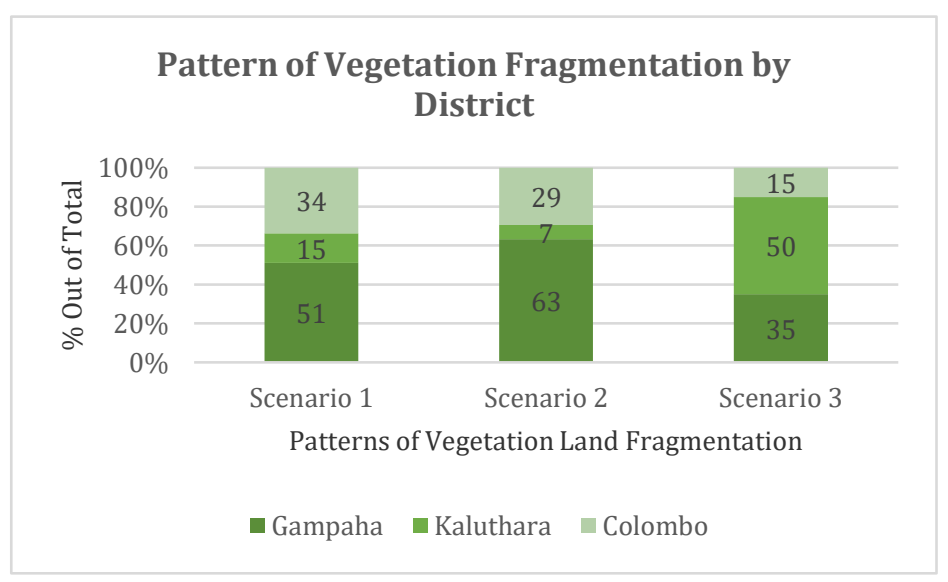

Figure 11, Districts' comparison of patterns of vegetation fragmentation (Source: Compiled by Author)

\section{Conclusion}

The research successfully achieved the research objectives of quantifying the level of vegetation land fragmentation, analyzing the level of vegetation land fragmentation and their patterns by district level. Therefore, the study successfully provides an initial step for the urban planners to understand the level of vegetation land fragmentation in the Sri Lankan Context. Key findings demonstrate that, ominously higher level of vegetation land fragmentation in the Gampaha District in the Western Province from 2000 to 2010 and 2010 to $2020.54 \%$ of GNDs in the Gampaha District have more than $60 \%$ of the level of vegetation land fragmentation from 2010-2010. It is 49\% from 2010-2020. The Colombo District indicates a moderate level of vegetation land fragmentation in most of the areas compared to the other two districts in both periods. It further shows the 36\% (2000-2010) and 53\% (2010-2020) of GNDs from 20\% to $40 \%$ level of vegetation land fragmentation. It reflects the level of land fragmentation is decreasing within the Colombo District. The Kaluthara District specifies a lower level of vegetation land fragmentation from 2000-2010. However, it is increasing from 2010-2020. Because 23\% (2000-2010) of GNDs have less than 20\% of the level of vegetation land fragmentation. However, it is $10 \%$ from $2010-2020$ and $22 \%$ of GNDs are $60 \%-80 \%$. In addition to that, Gampaha, Meerigama, Divlapitiya, Hanawella, Mathugama, Horana, Ingiriya, Homagama, Padukka areas show a significantly sophisticated level of vegetation land fragmentation during both periods. Therefore, it can be concluded that suburban areas are highly vulnerable to vegetation land fragmentation than urban areas. A substantial increment in the level of vegetation land fragmentation can be identified along the expressways and their interchanges during 2010-2020. Further, the study revealed the three main types of vegetation land fragmentation. The significant pattern is the process of dissecting, shrinking, and then disappearing. It is $46 \%$ out of the total 200 locations. Gampaha and Colombo indicate $51 \%$ and $34 \%$ of the same pattern distribution accordingly. Therefore, the study can synthesize the process or phases of the vegetation land fragmentation as dissecting, shrinking, and then disappearing.

Although the study has successfully achieved the objectives, the research is only limited to the Western Province in Sri Lanka. Therefore, future research can investigate with different case studies. Satellite images also contain less than $10 \%$ cloud concentration. Therefore, less than $20 \%$ of classification error is recorded as a limitation of this study. Therefore, clear satellite images need to utilize in future studies for highly accurate results. Further, future research can utilize different landscape metrics to verify the results. One of the limitations of this study is the validation of the results by using different techniques, especially ground verification and so on. Therefore, future research needs to use different quantification methods and validation methods to verify the study findings further. At the same time, it is essential to conduct future research to identify the factors of land fragmentation. More attention needs to provide on modeling vegetation land fragmentation. However, this study contributes its methodological application to quantify the vegetation land fragmentation and identification of the pattern of the vegetation land fragmentation. Therefore, this study provides an important initiation for land fragmentation studies and for urban planners to demonstrate land fragmentation in urban areas.

\section{Acknowledgment}

This research was supported by the 'Senate-Research-Committee' Grant, University of Moratuwa, Moratuwa, Sri Lanka (No SRC/ST/2021/12) 


\section{References}

Altinok, E. \& Cengiz, H., 2016. The Effects of Urban Sprawl on Spatial Fragmentation and Social Segregation in Istanbul. pp. 1-13.

Athukorala, D., Estoque, R., Murayama, Y. \& Matsushita, B., 2021. Impacts of Urbanization on the Muthurajawela Marsh and Negombo Lagoon, Sri Lanka: Implications for Landscape Negombo Lagoon, Sri Lanka: Implications for Landscape. Remote Sensing, pp. 1-20.

Balcik, F. B., 2016. Determination of Land Cover/Land Use Using SPOT 7 Data with Supervised Classification Methods. Remote Sensing and Spatial Information Sciences, pp. 143-146.

Barau, A. S. \& Qureshi, S., 2015. Using agent-based modelling and landscape metrics to assess landscape fragmentation in Iskandar Malaysia. SpringerOpen Journal, pp. 1-11.

Bereitschaft, B. \& Debbage, K., 2013. Regional Variations in Urban Fragmentation Among U.S. Metropolitan and Megapolitan Areas. Springer Science+Business Media Dordrecht, p. 119-147.

Forman, R., 2014. Land Mosaics: The Ecology of Landscapes and Regions (1995). In: The Ecological Design and Planning Reader. Washington: Islandpress, pp. 1-601.

Hedblom, M., 2008. Connectivity of nature in the Nordic countries (CONNOR). Roskilde Vandrehjem, Denmark, Nordic publications, pp. 1-77.

Huang, K., 2014. A Study on the Land-Cover Change Indicators of Taipei Metropolitan Areas. IOP Publishing Ltd, pp. 1-6.

Hudecova, L., Geisse, R., Silvia, G. \& Bajtala, M., 2018. Quantification of land fragmentation in Slovakia.

ResearchGate, pp. 327-338.

Irwin*†キ, E. G. \& Bockstael§, N. E., 2007. The evolution of urban sprawl: Evidence of spatial heterogeneity and increasing land fragmentation. The National Academy of Sciences of the USA, p. 20672-20677.

Jaeger, J., 2000. Landscape division, splitting index, and effective mesh size: new measures of landscape fragmentation. Landscape Ecology, pp. 115-130.

Jaeger, J. A. G., 2000. Landscape division, splitting index, and effective mesh size: new measures of landscape fragmentation. Landscape Ecology, pp. 115-130.

Jayasinghe, A. B. \& Munasinghe, J., 2013. A Study of the Urbanizing Pattern in Kegalle District, Sri Lanka with Connectivity Analysis. International Journal of Scientific Knowledge, Volume 2, pp. 1-19.

Jayasinghe, A., Madusanka, N. B. S., Abenayake, C. \& Mahanama, P. K. S., 2021. A Modeling Framework: To Analyze the Relationship between Accessibility, Land Use and Densities in Urban Areas. Sustainability, pp. 1-18.

Kalpana, L., Jayasinghe, A. \& Abenayake, C., 2019. Accessibilty Assessment of Cities Based on Network Analysis and Centrality. Journal of the Eastern Asia Society for Transportation Studies, Volume 13, pp. 1062-1096.

Kili'c, J., Jajac, N., Rogulj, K. \& Masteli'c-Ivi'c, S., 2019. Assessing Land Fragmentation in Planning Sustainable Urban Renewal. Sustainability, pp. 1-24.

Liang, X. et al., 2020. A research framework of land use transition in Suzhou City coupled with land use structure and landscape multifunctionality. Elsevier B.V., pp. 1-13.

Li, Q., Zhou, S. \& Wen, P., 2019. The relationship between centrality and land use patterns: Empirical evidence from five Chinese metropolises. Elsevier Ltd, pp. 1-13.

Li, T. et al., 2010. Fragmentation of China's landscape by roads and urban areas. Springer Science+Business Media, p. 839-853.

Liu, S. et al., 2017. Ecological Land Fragmentation Evaluation and Dynamic Change of a Typical Black Soil Farming Area in Northeast China. Sustainability, pp. 1-21.

Marinescu, I. E. \& Avram, S., 2012. Evaluation of urban fragmentation in Craiova city, Romania. Elsevier Ltd, pp. 207-215.

Piyumi, M., Abenayake, C., Jayasinghe, A. \& Wijegunarathna, E., 2021. Urban Flood Modeling Application: Assess the Effectiveness of Building Regulation in Coping with Urban Flooding Under Precipitation Uncertainty. Sustainable Cities and Society, Volume 75.

Saganeiti, L. et al., 2018. Assessing Urban Fragmentation at Regional Scale Using Sprinkling Indexes. sustainability, pp. 1-23.

Saganeiti, L. et al., 2018. Spatail Indicators to Evaluate Urban Fragmentation in Basilicata Region. Springer Nature, pp. 101-111.

Schumacher, U. \& Deilmann, C., 2019. Comparison of urban fragmentation in European cities: spatial analysis based on open geodata. Europa Regional, pp. 32-48.

Skog, K., 2016. How do centrality, population growth and urban sprawl impact farmland conversion in Norway?. Elsevier Ltd., pp. 185-196.

Thiele, J., Schuckert, U. \& Otte, A., 2008. Cultural landscapes of Germany are patch-corridor-matrix mosaics for an invasive megaforb. Landscape Ecology, pp. 23(4): 453-465.

Un, C. et al., 2008. Evaluating Urbanization, Fragmentation and Land Use/Land Cover Change Pattern in Istanbul City Turkey from 1971 to 2002. Wiley InterScience, pp. 663-675. 
Verburg, P. H., Nijs, T. D., Eck, J. R. V. \& Dijst, M., 2004. Determinants of land-use change patterns in the Netherlands. Environment and Planning B: Planning and Design, pp. 125-150.

Wei, Y. \& Zhang, Z., 2011. Assessing the fragmentation of construction land in urban areas: An index method and case study in Shunde, China. Elsevier Ltd, pp. 417-428.

Wickramaarachchi, N. C. \& Weerahewa, J., 2016. Land Fragmentation and Land Productivity: Empirical Evidence from Land Distribution Schemes of Sri Lanka. International Academic Research Journal of Business and Management, pp. 11-21.

Wu, J., 2013. Landscape Ecology. ResearchGate, pp. 5772-5784.

York, A. M. et al., 2011. Land fragmentation under rapid urbanization:A cross-site analysis of Southwestern cities. Springer Science+Business Media, p. 429-455.

You, H., 2016. Quantifying Urban Fragmentation under Economic Transition in Shanghai City, China. sustainability, pp. 1-12. 